\title{
RE-ENGINEERING PROSES PEMBELIAN BARANG AKTIVA DALAM MENCAPAI PEMBELANJAAN YANG OPTIMUM DALAM BISNIS MIDDLE MARKET STUDI KASUS: PT. Midi Utama Indonesia Tbk/Alfamidi
}

\author{
Heri Muryanto \\ Dosen Fakultas Teknik Prodi Teknik Industri Universitas Pamulang \\ Dosen00913@unpam.ac.id
}

\begin{abstract}
Penelitian ini merupakan studi kasus pada perusahaan ritel, yaitu PT. Midi Utama Indonesia Tbk / peraturan terkait Alfamidi untuk memenuhi empat pembelian tepat adalah harga yang tepat, waktu, jumlah dan kualitas dan cara mendapatkan model optimal pembelian barang. Metode penelitian berupa analisis deskriptif melalui survei kuesioner dan wawancara dengan karyawan perusahaan yaitu sebanyak 153 karyawan dengan sampel 111 responden. Data diolah dengan Analisis Regresi Linier Berganda yang bernilai signifikan adalah total pembelian standar yaitu total pembelian 0,061 dan 0,000 , dan hasil dari SWOT menyatakan perlu melakukan strategi yang berfokus pada proses peningkatan pembelian. Hasil bahwa proses proses re-engineering melibatkan pembelian barang dengan departemen GA untuk lebih memastikan ketersediaan barang yang akan dipesan, sehingga pembelian benar-benar terkontrol
\end{abstract}

Kata Kunci : SWOT, pembelian, GA, optimimum

\section{PENDAHULUAN}

Dalam menghadapi masa globalisasi seperti saat ini, persaingan dalam industri retail menjadi pesat untuk persaingan dan tentu saja harus menjadi yang terbaik dan harus dapat ber inovasi terutama dalam hal penjualan barang atau produk, maka tidak hanya dapat mengadalkan pasar semata namun terdapat pula alternatif untuk melakukan ekspansi didalam proses penjualan suatu produk, terutama dalam hal yang dapat dijangkau oleh banyak kalangan masyarakat. Oleh sebab itu salah satunya adalah dengan mendirikan usaha di bidang ritel.

Menyadari akan adanya peluang bisnis yang menjanjikan maka dalam hal ini PT. Midi Utama Indonesia Tbk muncul untuk menjawab tantangan peluang bisnis di bidang retail ini. Dengan mengusung kepuasan pelanggan dengan memberikan service yang baik berupa tempat yang nyaman dan mudah dijangkau, tidak hanya itu PT. Midi Utama Indonesia Tbk yang lebih dikenal di masyarakat dengan nama Alfamidi juga menawarkan beberapa kelebihan diantaranya ketersediaannya barang-barang yang dibutuhkan oleh masyarakat di sekitar area tersebut. Seperti sayuran, aneka makanan ringan dan kebutuhan rumah tangga lainnya.

Alfamidi dengan tagline "Belanja Puas Harga Hemat" diposisikan untuk dapat memberikan pelayanan dan pengalaman belanja pelanggan agar terpenuhi kebutuhannya dan dengan harga yang hemat.

Alfamidi sebagai "gerai komunitas", berlokasi di wilayah pemukiman agar dapat melayani dengan cepat dan mudah dijangkau masyarakat dari rumah. Sebagai gerai komunitas, Alfamidi juga mengajak masyarakat sekitar gerai untuk dapat berusaha/berdagang dengan menempati area depan samping gerai.

Alfamidi yang saat ini bergerak dibidang ritel ini juga akan mengusung ekspansi yang lebih luas lagi untuk membuka gerai nya di beberapa lokasi lain mengingat akan kebutuhan pasar yang semakin bertumbuh pesat dan semoga dengan adanya Alfamidi ini akan membantu masyarakat dalam pemenuhan kebutuhan dan dapat membantu pemerintah didalam penyerapan tenaga kerja. 


\section{DASAR TEORI}

\section{A. Teori Pembelian}

1. Menurut Riyanto, Bambang (1995) dalam buku "Dasar-dasar pembelian" menyatakan bahwa, pembelian merupakan sistem aplikasi siklus pengeluaran yang umum.

2. Menurut Sofjan Assauri, (2008: 223), Pembelian adalah salah satu fungsi yang penting dalam berhasilnya operasi suatu perusahaan

3. Menurut Soemarsono. S.R (2009:208) dalam bukunya yang berjudul akuntansi pengantar menyatakan bahwa, pembelian adalah akun yang digunakan untuk mencatat semua pembelian barang dagang dalam suatu periode.

4. Menurut Bodnar dan Hopwood (2006:417) yaitu Procurement is the business proces of selecting a source, ordering,and acquaring goods or service.

5. Menurut Susan Irawati (2008:64) dalam bukunya yang berjudul Manjemen keuangan yang menyatakan bahwa pembelian adalah suatu kegiatan untuk memperoleh sejumlah harta atau aktiva maupun jasa dari satu pihak untuk kelangsungan usaha atau kebutuhan yang mendasar,sehingga dilakukan pembayaran atas sejumlah uang atau jasa tersebut, untuk kelangsungan operasional perusahaan.

6. Sedangkan menurut Mulyadi (2007,p.711) aktivitas dalam proses pembelian barang adalah: Permintaan pembelian., Pemilihan pemasok, Penempatan order pembelian, Penerimaan barang, Pencatatan transaksi pembelian.

7. Menurut Ir. Revino, SE.,M.M.(106:2) dengan judul Purchasing Suatu Pengantar Praktis Edisi 2006, menerangkan definisi purchasing berintikan kegiatan badan meyeluruh yang berfokus pada pengadaan material suplai dan jasa yang dibutuhkan untuk mencapai tujuan organisasi. Dalam pandangan sempit, purchasing dilukiskan sebagai proses membeli; dalam arti yang lebih luas purchasing berfungsi dalam menentukan kebutuhan memilih pemasok; kedatangan sesaui waktu, harga, bentuk dan kondisi yang layak; menerbitkan kontrak atau order dan memastikan pengiriman.

8. Menurut Budiharjo Hardjowijono dan Hayie Muhammad (2008) persediaan barang dan jasa harus dilaksanakan berdasarkan prinsip pengadaan yang dikelola secara internasional efisiensi, efektifitas, persaingan sehat, keterbukaan, transpraransi, dan akuntabilitas

\section{B. Tahap-tahap Prosedur Pembelian}

\section{Prosedur permintaan pembelian}

Dalam prosedur permintaan yakni fungsi gudang mengajukan permintaan pembelian dalam bentuk formulir surat pengajuan pembelian kepada divisi pembelian. Jika barang tidak disimpan di gudang, misalnya untuk barang-barang yang langsung dipakai, fungsi yang memakai barang mengajukan permintaan pembelian langsung ke divisi pembelian dengan menggunakan surat pengajuan permintaan pembelian barang.

2. Prosedur permintaan penawaran harga pemilihan supplier

Prosedur ini fungsi divisi pembelian mengirimkan surat penawaran harga kepada para supplier untuk memperoleh informasi harga barang dan berbagai syarat pembelian yang lain, demi memungkinkan pemilihan supplier yang akan ditunjukan sebagai supplier barang yang diperlukan oleh perusahaan.

\section{Prosedur order pembelian}

Dalam prosedur ini divisi pembelian mengirimkan surat order pembelian kepada supplier yang dipilih dan memberitahukan kepada divisi lain dalam perusahaan (misalnya divisi penerimaan, divisi yang meminta barang dan divisi pencatatan 
utang) mengenai order pembelian yang sudah dikeluarkan oleh perusahaan.

\section{Prosedur penerimaan barang}

Prosedur ini divisi penerimaan melakukan pemeriksaan mengenai jenis, kualitas dan mutu barang yang diterima dari supplier dan membuat laporan penerimaan barang untuk menyatakan barang dari supplier tersebut apakah sesuai permintaan atau tidak, jika terjadi ketidaksesuaian maka barang tersebut wajib dikembalikan ke supplier di hari yang sama lalu surat jalannya dicoret sesuai jumlah barang yang diterima.

\section{Prosedur pencatatan utang}

Dalam prosedur ini divisi akuntansi memeriksa dokumen yang berhubungan dengan pembelian (surat order pembelian/Purchasing Order, laporan penerimaan barang dan faktur dari supplier).

\section{Prosedur distribusi pembelian}

Prosedur ini yakni meliputi distribusi rekening untuk didebet dari transaksi pembelian demi kepentingan pembuatan laporan manajemen dalam sebuah perusahaan.

\section{Beberapa prinsip dalam Procurement}

Menurut Budiharjo Hardjowijono dan Hayie Muhammad (2008) persediaan barang dan jasa harus dilaksanakan berdasarkan prinsip pengadaan yang dikelola secara internasional efisiensi, efektifitas, persaingan yang sehat, keterbukaan, transpraransi, dan akuntabilitas.

\section{Efisiensi}

Prinsip efisiensi dalam persediaan barang dan jasa untuk menggunakan sumber daya yang tersedia demi memperoleh barang dan jasa dalam jumlah dan kualitas yang diharapkan dengan waktu yang optimal.

\section{Efektif}

Prinsip efektif dalam persediaan barang dan jasa dengan sumber daya yang tersedia untuk perolehan barang dan jasa yang mempunyai nilai manfaat maksimal dan optimum.

\section{Persaingan Sehat}

Prinsip persaingan sehat dalam persediaan barang dan jasa yaitu adanya persaingan antar calon penyedia barang dan jasa berdasarkan etika dan norma persediaan yang berlaku, dan tidak terjadi kecurangan.

\section{Terbuka}

Prinsip terbuka dalam pengadaan barang dan jasa yakni memberikan kesempatan kepada semua para penyedia barang dan jasa yang kompeten untuk mengikuti pengadaan sesuai ketentuan yang berlaku.

\section{Transparansi}

Prinsip transparansi untuk persediaan barang dan jasa yaitu memberikan informasi yang lengkap tentang aturan pelaksanaan pengadaan barang dan jasa kepada semua calon penyedia barang dan jasa yang berminat dalam mengikuti proses persediaan barang tersebut.

\section{Akuntabilitas}

Prinsip akuntabilitas dalam persediaan barang dan jasa adalah pertanggungjawaban pelaksanaan penyediaan barang dan jasa kepada para pihak yang terkait berdasarkan etika, norma, dan ketentuan peraturan perundang-undangan yang berlaku.

\section{METODE PENELITIAN}

Jenis penelitian ini adalah penelitian deskriptif dengan menggunakan survey. Penelitian deskriptif dapat diartikan sebagai proses pemecahan masalah yang diselidiki dengan melukiskan keadaan subyek dan obyek penelitian pada saat sekarang berdasarkan fakta-fakta yang tampak atau sebagaimana adanya. Pelaksanaan metode penelitian deskriptif tidak terbatas sampai pada pengumpulan dan penyusunan data, tetapi meliputi analisis dan interprestasi tentang data tersebut serta mewujudkannya menjadi rancangan teknis, selain itu semua 
yang dikumpulkan memungkinkan menjadi kunci terhadap apa yang diteliti.

Dalam penelitian ini, data bersumber dari PT. Midi Utama Indonesia Tbk. Jl. MH. Thamrin No. 9 Cikokol - Tangerang, pada Departemen di Head Office yang berada di departemen berikut : Marketing, Finance, S\&D, Operation, Akunting, Merchandising, General Affair, IT, Pengambilan data dilakukan melalui penyebaran kuesioner, wawancara, dan pengamatan langsung.

Dari hasil data yang terrecord dari bulan Januari 2014 sampai dengan Oktober 2016 melalui data pembelian barang aktiva yakni barang peralatan di PT. Midi Utama Indonensia Tbk.

Variabel merupakan obyek penelitian atau apa saja yang menjadi titik perhatian dalam suatu penelitian tersebut tertuang dalam isi dari variabel pertanyaan yang diajukan oleh penulis ke responden.

Dalam variabel yang berkaitan dengan proses Re-engineering proses pembelian barang aktiva di PT. Midi Utama Indonesia Tbk sangatlah banyak variannya, dalam hal ini penulis menitikberatkan kepada faktorfaktor yang sangat berperngaruh dan juga memberikan inovasi program proses pembelian terbarukan dengan memberikan wacana E-Procurement, meskipun dalam inovasi tersebut di PT. Midi Utama Indonesia Tbk belum dapat diterapkan dan masih baru, dalam hal ini penulis ingin mengetahui respon para responden dalam keingintahuannya mengenai hal ini, berikut pertanyaan dalam variabel yang dibuat oleh penulis:

1. Waktu penerimaan barang dari supplier

2. Waktu penerimaan barang di Internal

3. Standar pembelian

4. Harga barang

5. E-Procurement

6. Purchase order

7. Faktor keterlambatan pembelian barang di Internal
Langkah awal yang akan dilakukan dalam penelitian ini adalah pengolahan data. Pengolahan data dilakukan dengan menggunakan program Microsoft Office Excel 2010 lau dilanjut dengan SPSS 22 dan berdasarkan pada hasil pengolahan program tersebut, data akan dianalisis secara deskriptif.

\section{IV.HASIL DAN PEMBAHASAN}

Penelitian yang dilakukan terhadap sebuah perusahaan retail ini terdiri dari Populasi yang ada yaitu sebanyak 153 orang yang bersumber dari berbagai divisi, pemilihan responden diperoleh dari berbagai divisi yang berhubungan dengan proses pengadaan barang terutama dari sumber yang akan membeli barang dan yang menerima barang, untuk menentukan sample menggunakan rumus slovin untuk mempermudah bagi peneliti dalam menentukan jumlah orang yang akan dimintakan data kuesioner.

Jumlah populasi 153 orang dengan taraf kesalahan yang digunakan peneliti yakni $5 \%$ maka dapat dilakukan perhitungan sebagai berikut:

$$
\mathrm{n}=\frac{153}{1+153 \times 0,05^{2}}=110,669
$$

Berdasarkan hasil perhitngan tersebut maka sample yang diambil dari 9 departemen yakni 111 pembulatan dari hasil perhitungan 110,669 .

Dalam penelitian ini, uji validitas dan realibilitas kuesioner dilakukan untuk dapat menentukan apakah bentuk pertanyaan/questionnaire tersebut valid dan reliabel untuk diteruskan, sehingga pertanyaan-pertanyaan yang akan diberikan berkesuaian dan tepat sasaran mengenai kondisi penelitian seputar pembelian di PT. Midi Utama Indonesia Tbk atau Alfamidi, antara kepuasan user terhadap performa pembelian dan harapan user dilakukan dengan menggunakan teknik Croanbach's dengan perhitungan menggunakan SPSS, 
adapun hasil dalam perhitungan validitas dan realibilitas pada penelitian ini dapat dilihat, sebagai berikut:

Sebelum melakukan penelitian dengan menyebarkan questionnaire maka peneliti wajib membuatkan pertanyaan yang bisa dipahami oleh calon responden dan disesuaikan dengan keadaan yang sebenarnya. Jumlah responden yang disurvey ada 111 orang

\begin{tabular}{|c|c|c|}
\hline NO & DEPARTEMEN & $\begin{array}{l}\text { JUMLAH } \\
\text { (ORANG) }\end{array}$ \\
\hline 1 & MARKETING & 20 \\
\hline 2 & FINANCE & 16 \\
\hline 3 & S\&D & 10 \\
\hline 4 & OPERATION & 20 \\
\hline 5 & AKUNTING & 10 \\
\hline 6 & MERCHANDISING & 15 \\
\hline 7 & GENERAL AFFAIR & 10 \\
\hline 8 & IT & 10 \\
\hline \multicolumn{2}{|r|}{ TOTAL } & 111 \\
\hline
\end{tabular}

Sumber: PT. Midi Utama Indonesia Tbk Dari data jumlah responden tersebut kemudian disebarkan pertanyaan dalam bentuk kuesioner dan selanjutnya dimasukan dalam penghitungan data dengan menggunakan SPSS, untuk menguji hasil validitas dan realibilitas.

Disamping pengujian secara hasil validitas dan realibilitas pengujian pun dilakukan dengan beberapa metode yang terkandung dalam SPSS seperti Analisis data deskriptif, uji asumsi klasik persamaan regresi linier berganda yang terdiri dari uji normalitas, uji multikolonieritas, uji heteroskedastisitas.

Pengujian yang dilakukan oleh penelitian disini ditambahkan dengan pengujian SWOT yang dilakukan melalui 3 tahapan.

\section{Tahap pengambilan data}

Tahap pengambilan data ini digunakan untuk mengetahui faktor-faktor yang menjadi kekuatan, kelemahan, peluang dan ancaman bagi perusahaan dan dilakukan dengan tahapan pengambilan data melalui proses wawancara terhadap
GM Operation di PT. Midi Utama Indonesia Tbk di Head Office.

\section{Tahap Analisis}

Tahap analisis yaitu pembuatan matriks internal eksternal dan matriks SWOT. Setelah mengetahui berbagai faktor dalam perusahaan maka tahap selanjutnya adalah membuat matriks internal dan eksternal. Matriks SWOT menggambarkan secara jelas bagaimana peluang dan ancaman eksternal yang dihadapi oleh perusahaan yang dapat disesuaikan dengan kekuatan dan kelemahan yang dimiliki. Kemudian dari matriks ini akan terbentuk empat kemungkinan alternatif strategi.

\section{Tahap pengambilan keputusan}

Dalam tahap pengambilan keputusan, matriks SWOT ini perlu merujuk kembali matriks internal eksternal yang menghasilkan posisi perusahaan saat ini.

Pada penelitian ini, analisa siatuasi atau analisa SWOT dilakukan dengan cara melakukan wawancara terhadap responden yakni GM Operation di PT. Midi Utama Indonesia Tbk/Alfamidi.

Terdapat 2 faktor yakni eksternal dan internal:

\section{Faktor Eksternal}

1. Faktor-faktor yang menjadi peluang (Opportunities)
a. X5 - E-Procurement
b. X8 - Kriteria supplier

2. Faktor-faktor yang menjadi ancaman (Threats)

a. X1 - Waktu penerimaan barang dari supplier

b. X2 - Waktu penerimaan barang di internal dari GA

\section{Faktor Internal}

1. Faktor-faktor yang menjadi kekuatan (Strength)

a. X3 - Standar Pembelian

b. X6 - Purchase order

2. Faktor-faktor yang menjadi kelemahan (weakness)

a. X4 - Harga barang

b. X7 - Faktor keterlambatan pembelian 


\begin{tabular}{|c|c|c|c|c|c|}
\hline arraber & Koef & Strd. Error & Std. Koef & $\mathrm{T}$ & Sig \\
\hline konstanta & 0.033 & 2,173 & & 0.015 & 0,988 \\
\hline 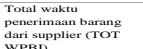 & 0,229 & 0.199 & 0,111 & 1,153 & 0,252 \\
\hline $\begin{array}{l}\text { Total standar } \\
\text { pembelian (TOT SP) }\end{array}$ & 0,260 & 0,137 & 0,158 & 1.896 & 0,061 \\
\hline $\begin{array}{l}\text { Total purchase order } \\
\text { (TOT PO) }\end{array}$ & 1,014 & 0,117 & 0,884 & 8,702 & o,o00 \\
\hline $\begin{array}{l}\text { Total faktor } \\
\text { keteriambanatan } \\
\text { pembelian secara } \\
\text { internal (TOT } \\
\text { FKPI) } \\
\text { FKPI }\end{array}$ & $-0,123$ & 0,084 & -0.090 & $-1,468$ & 0,145 \\
\hline $\begin{array}{l}\text { Total } \\
\text { E-procurement } \\
\text { (TOT EP) }\end{array}$ & $-0,209$ & 0,234 & -0.134 & $-0,896$ & 0,373 \\
\hline
\end{tabular}

Tabel 5.21 Analisis Hasil Regresi Linier Berganda

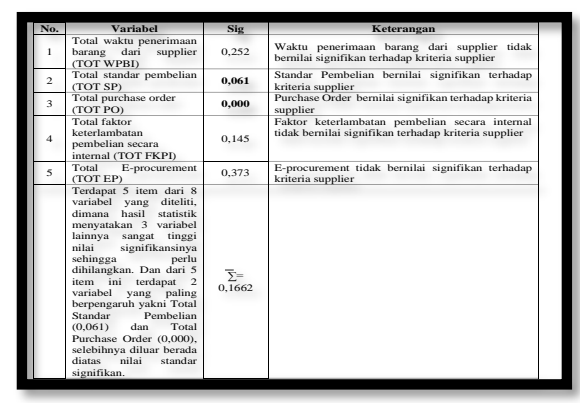

Sesuai dengan hasil analisis eksternal dan internal diatas, maka dapat disampaikan matriks SWOT guna memformulasikan

Pada hasil matrix swot diatas, diharapkan tesis ini memberikan kontribuasi bahwasannya masih banyak yang perlu dipersiapkan dalam menyusun strategi apa

\section{V.KESIMPULAN}

Berdasarkan hasil penelitiian yang telah dilakukan dalam metode SWOT untuk menyelesaikan permasalahn $4 \mathrm{~T}$, yaitu tepat harga, tepat waktu, tepat jumlah dan tepat mutu dan perhitungan melalui SPSS untuk menentukan proses pembelian barang secara optimum sesuai hasil analisa regresi linier berganda pada barang aktiva di PT. Midi Utama Indonesia Tbk maka dapat disimpulkan sebagai berikut:

1. Mengenai tepat harga, didapat dari hasil SWOT menyatakan bahwa Harga barang dan faktor keterlambatan pembelian secara internal menurut GM operation harus ditingkatkan dengan menyusun strategi yang berfokus pada tenderisasi harga diawal yang menyangkut kontrak
Sumber : Data primer yang diolah

Pada proses pengolahan data, penguji melakukan tiga kali tahapan proses untuk menyatakan bahwa data yang akan diproses harus dapat menyatakan mengenai hipotesis variabel mana saja yang saling memiliki pengaruh terhadap variabel yang ditentukan dengan nilai minimal $0,000-0,10$.

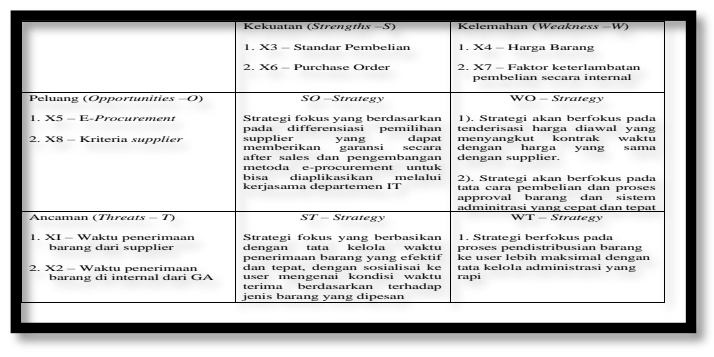

Sumber : Data primer yang diolah

\subsubsection{Matriks SWOT}

strategi bagi re-engineering proses pembelian barang aktiva dalam mencapai pembelanjaan yang optimum bisnis middle market melalui perusahaan PT. Midi Utama Indonesia Tbk seperti Tabel 5.23 dibawah ini.

yang perlu dan yang tidak perlu, sehingga pembelian bisa lebih ditekan dengan nilai efisiensi yang baik dan sistem kedatangan waktu bisa diprediksi dengan baik

waktu dengan harga yang sama dengan supplier, lalu secera internal tata cara proses approval barang dan administrasi yang cepat dan tepat.

2. Mengenai tepat waktu didapat dari hasil SWOT yang menyatakan bahwa ketepatan waktu sudah menjawab dimana input dari GM operation yang memasukan faktor waktu penerimaan barang dari supplier dan waktu penerimaan barang di internal dari GA menjadi strategi yang memfokuskan pada basis tata kelola waktu penerimaan yang efektif dan tepat, dengan sosialisasi ke user mengenai kondisi waktu terima berdasarkan jenis barang yang dipesan. 
3. Mengenai tepat jumlah didapat dari hasil SWOT yang berhubungan dengan ketepatan jumlah barang yang dipesan dimana input dari GM operation yang memasukan faktor E-procurement dan kriteria supplier, dimana strategi akan memfokuskan pada differensiasi pemilihan supplier yang dapat memberikan pelayanan maksimal mengenai sistem kelola pemenuhan barang yang ditentukan diawal penawaran harga dikarenakan setiap supplier memiliki kriteria berbeda dalam memandang kuantiti barang sehingga perlu adanya kriteria supplier yang dapat menerima permintaan pembelian baik itu skala kecil, sedang dan besar dan memasukan proses e-procurement untuk lebih spesifik memastikan jumlah barang yang akan dipesan dengan aktual.

4. Mengenai tepat mutu didapat dari hasil SWOT yang berhubungan dengan ketepatan mutu dimana input dari GM operation yang memasukan faktor Standar pembelian dan purchase order, dimana mutu suatu barang harus benar-benar diperhatikan karena jika mutu yang diperoleh tidak bagus maka akan rugi secara biaya/cost maka standar pembelian dan purchase order harus diperjelas sehingga semua pihak dapat menerima pelayanan dan kinerja yang maksimal, di dalam PO harus diterapkan spesifikasi yang jelas sehingga hasil pembelian bisa optimum.

Menanggapi proses bagaimana model untuk meningkatkan meningkatkan proses pembelian barang secara optimum sesuai dengan hasil analisa regresi linier berganda dinyatakan bahwa terdapat dua faktor yang nilai signifikansinya yang memasuki nilai standar antara 0,05-0,10 yakni ada dua variabel total standar pembelian dimana nilai signifikansi 0,061 dan total purchase order dengan nilai signifikansinya adalah 0,000 dari hasil temuan tersebut maka perlu ditingkatkan kembali dari sisi kekuatan dan kejelasan mengenai tata cara proses pembelian yang benar dan juga purchase order yang benar-benar akurat sesuai dengan permintaan kesepakatan semua pihak baik itu supplier maupun user agar semuanya terpuaskan dan proses pembelian pun menjadi optimum.

\section{DAFTAR PUSTAKA}

Achmad Yanu Alif Fianto, Djumilah Hadiwidjojo, Siti Aisjah, Solimun, 2014, The influence of brand image on purchase behaviour through brand trust. Jurnal: Universitas Brawijaya

Amelia, Hendro Susanto, Melisa, 2014, Analisis Faktor-Faktor yang Mempengaruhi Purchase Intention Produk Mango di Surabaya. Jurnal: Universitas Pelita Harapan

Annual Report PT. Midi Utama Indoensia Tbk, 2014, 2015 dan 2016

Bowersox, Donald J. diterjemahkan oleh Drs. A. Hasymi Ali. 1978, Manajemen Logistik 1 Integrasi Sistem-sistem Manajemen Distribusi Fisik dan Manajemen Material. Penerbit, Bumi Aksara

Bowersox, Donald J. diterjemahkan oleh Drs. A. Hasymi Ali. 1978, Manajemen Logistik 2 Integrasi Sistem-sistem Manajemen Distribusi Fisik dan Manajemen Material. Penerbit, Bumi Aksara

Curkovic, Sime, Scannell, Thomas, Wagner, Bret, 2016, Managing Supply Chain Risk Integrating with Risk Management, Taylor and Francis Group, LLC, Boca Raton, New york, America

Damayanti, Amelia Iftitah. Tjahjanulin Domai, Abdul Wachid, 2012, Penerapan E-Procurement dalam proses pengadaan barang/jasa di Kabupaten Malang (Studi Pada Bidang Asset Dinas Pendapatan, Pengelolaan Keuangan dan Asset Kabupaten Malang. Jurnal: Universitas Brawijaya

Dinawan, M Rheindra April, 2010, Analisis Faktor-faktor yang Mempengaruhi keputusan Pembelian, studi kasus pada konsumen Yamaha Mio PT. 
Harpindo Jaya Semarang, Dalam Penelitian Untuk Tesis Magister Managemen, Universitas Diponegoro Revino, 2006. Purchasing Suatu Pengantar Praktis. PT. Penerbit Djambatan

Supriyadi , Edy. 2014. SPSS+AMOS Statistical Data Analysis, Penerbit, in media

Jurnal: $\quad$ Universitas $\quad$ Trisakti.
Susanti, Era, 2008, Analisis pengaruh brand equity terhadap keputusan pembelian konsumen Studi kasus di Jco Donuts \& Coffee, Tesis: Universitas Indonesia

Sutrisno, Nuno, 2014, Pengaruh implementasi supply chain integration, just in time purchasing dan just in time manufacturing terhadap logistic performance. 